\title{
Dermoscopy applied to pediculosis corporis diagnosis*
}

\author{
Luiz Gustavo Martins ${ }^{1}$ \\ Thiago Rubin Bellott ${ }^{3}$
}

\author{
Fred Bernardes Filho ${ }^{2}$ \\ Larissa Nascimento Botelho ${ }^{4}$
}

Maria Victória Quaresma²
Ana Cecília Studart Prata

DOI: http://dx.doi.org/10.1590/abd1806-4841.20142654

Abstract: We report the case of a 47-year-old homeless male with a massive infestation of Pediculus humanus corporis on his entire body. Dermoscopy helped to diagnose pediculosis by showing the involvement of scalp, beard and the genital region in this disease.

Keywords: Dermoscopy; Lice infestations; Pediculus

A 47-year-old male patient assisted by the Medical Emergency Assistance Service was taken to the emergency unit presenting with dehydration. He reported itching on his entire body. Dermatological examination revealed the presence of excoriated lesions at the occipital and cervical regions, as well as lice and several white spots adhered to beard hairs (Figure 1 and Video 1). Pubic hairs were also infested (Figure 1 and Video 2). Additionally, the patient also presented with hyperchromic lesions on the lower limbs (Figure 2).

Dermoscopy showed several nits and lice on the scalp and a great number of nits, nymphs and lice on the beard and also on the genital region (Figures 2 and 3). Lice were identified as Pediculus humanus corporis. Hospitalization and rehydration were recommended. Dermatosis was treated with oral ivermectin and shaving of body and head hair.
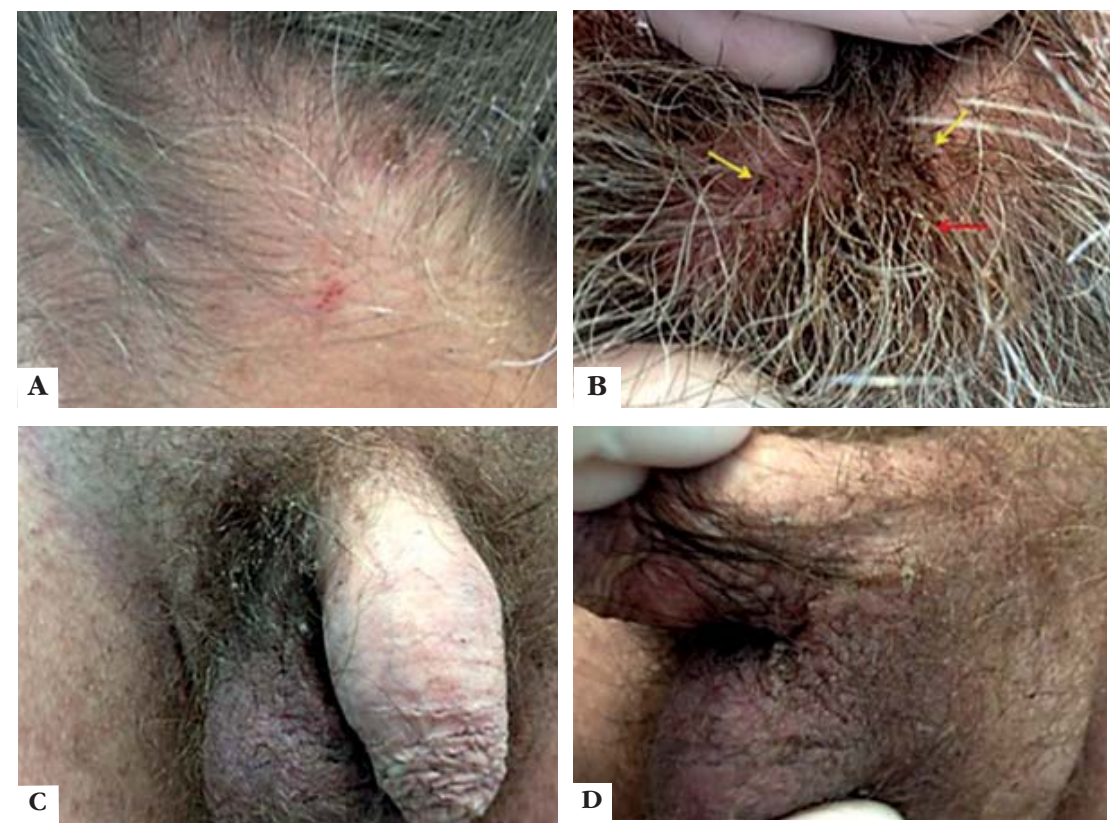

FIGURE 1:

(A) Excoriated lesions at occipital and cervical regions; (B) Presence of lice (yellow arrows) and several white spots on the beard (red arrow); (C, D) Countless white spots and lice in pubic hairs

Received on 26.03.2013.

Approved by the Advisory Board and accepted for publication on 15.04.2013.

* Study conducted at Visiaderm clinic - Ituiutaba (MG), Brazil.

Conflict of interest: None

Financial funding: None

Private Practice Ituiutaba (MG), Brazil.

Santa Casa da Misericórdia do Rio de Janeiro (SCMRJ) - Rio de Janeiro (RJ), Brazil.

Universidade Federal Fluminense (UFF) - Rio de Janeiro (RJ), Brazil.

Escola de Medicina Souza Marques - Rio de Janeiro (RJ), Brazil. 
Video available online at

http://www.anaisdedermatologia.org.br/

\section{Video 1:}

Detail of a great number of lice and nits on patient's beard

Video 2:

Dermoscopy presenting one louse during blood meal. It is possible to observe blood in its intestinal tube
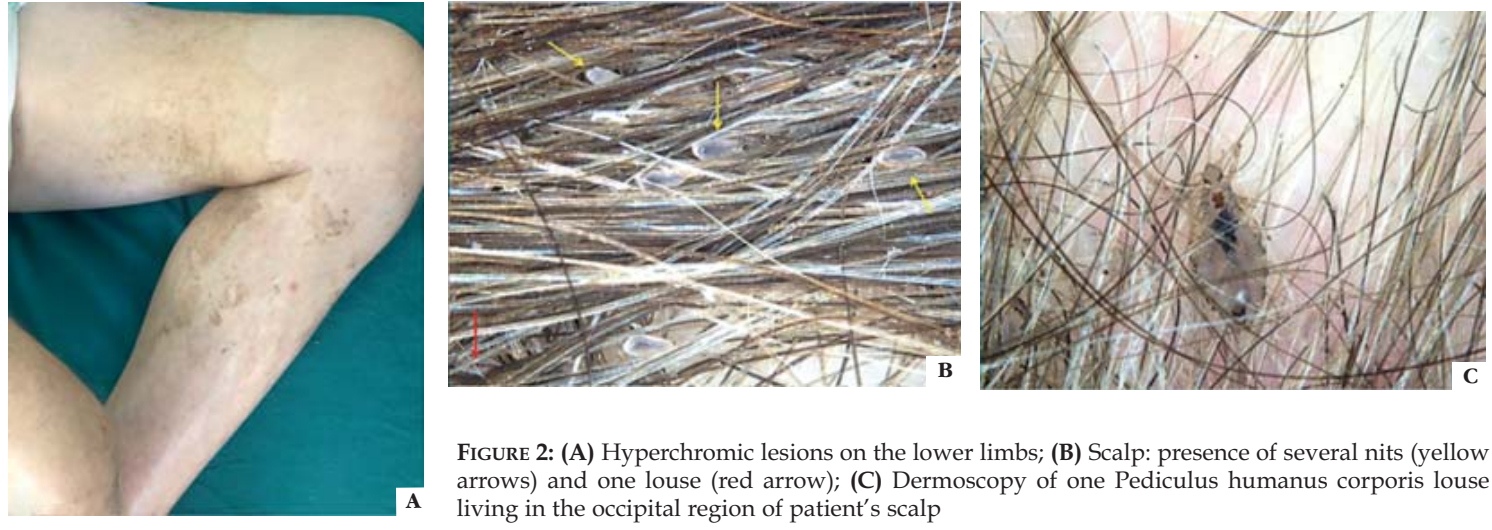

Figure 2: (A) Hyperchromic lesions on the lower limbs; (B) Scalp: presence of several nits (yellow arrows) and one louse (red arrow); (C) Dermoscopy of one Pediculus humanus corporis louse living in the occipital region of patient's scalp
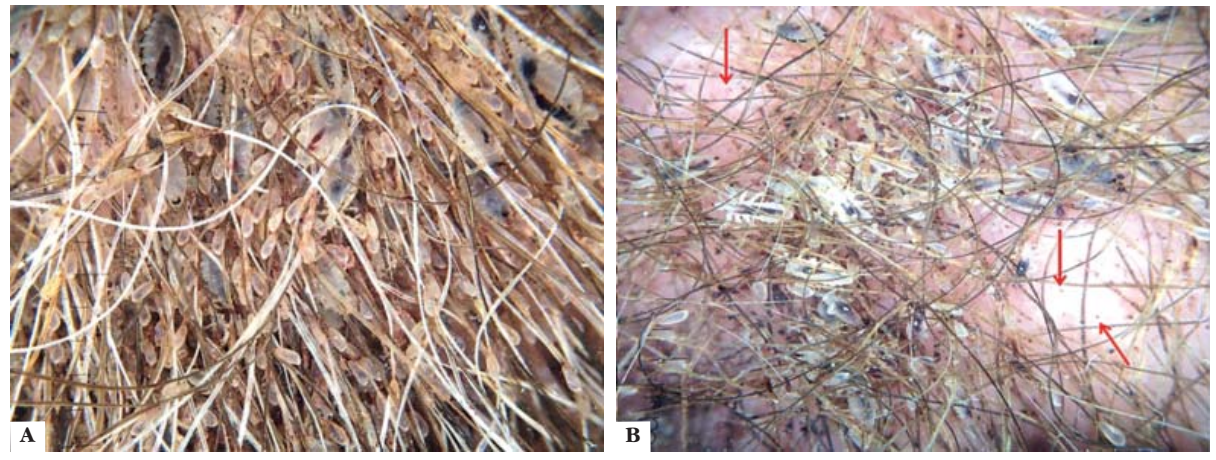

Figure 3:

(A) Dermoscopy of patient's beard showing the presence of countless nits, nymphs and lice; (B) Dermoscopy showing several lice, nits and stinging spots (red arrows)

Pediculosis is a condition that has been affecting humanity over the entire history. ${ }^{1}$ Pediculosis corporis manifests as urticarial papular and hemorrhagic lesions, mainly on the trunk, abdomen and buttocks, as well as excoriations, lichenification, and hyperchromia, characterizing the so-called "vagabond's dis- ease". ${ }^{2}$ Entodermoscopy or dermoscopy proved to be an useful auxiliary tool in the diagnosis and treatment follow-up of pediculosis, because it identifies Pediculus humanus corporis in detail on all sites infected by lice. ${ }^{3} \square$

\section{REFERENCES}

1. Neira PE, Molina LR, Correa AX, Américo Muñoz NR, Oschilewski DE. Metal microchanelled fine-toothed comb use in the diagnosis of pediculosis. An Bras Dermatol. 2009;84:615-21.

2. Whittield A. Case of Vagabond's Disease. Proc R Soc Med. 1926;19:31.

3. Criado PR. Entodermoscopy: dermoscopy for the diagnosis of pediculosis. An Bras Dermatol. 2011;86:370-1.

\author{
MAILING ADDRESS: \\ Luiz Gustavo Martins \\ Rua 38, n० 936 - Progresso \\ 38302-010 - Ituiutaba - MG \\ Brazil \\ E-mail: luizgustavodermatologia@gmail.com
}

How to cite this article: Martins LG, Bernardes Filho F, Quaresma MV, Bellott TR, Botelho LN, Prata ACS. Dermoscopy applied to pediculosis corporis diagnosis. An Bras Dermatol. 2014;89(3):513-4. 